\title{
SIMULATING OZONE EFFECTS ON FOREST PRODUCTIVITY: INTERACTIONS AMONG LEAF-, CANOPY-, AND STAND-LEVEL PROCESSES
}

\author{
Scott V. Ollinger, ${ }^{1}$ John D. Aber, ${ }^{1}$ And Peter B. Reich ${ }^{2}$ \\ ${ }^{1}$ Complex Systems Research Center, Institute for the Study of Earth, Oceans and Space, \\ University of New Hampshire, Durham, New Hampshire 03824 USA \\ ${ }^{2}$ Department of Forest Resources, University of Minnesota, St. Paul, Minnesota 55108 USA
}

\begin{abstract}
Ozone pollution in the lower atmosphere is known to have adverse effects on forest vegetation, but the degree to which mature forests are impacted has been very difficult to assess directly. In this study, we combined leaf-level ozone response data from independent ozone fumigation studies with a forest ecosystem model in order simulate the effects of ambient ozone on mature hardwood forests. Reductions in leaf carbon gain were determined as a linear function of ozone flux to the leaf interior, calculated as the product of ozone concentration and leaf stomatal conductance. This relationship was applied to individual canopy layers within the model in order to allow interaction with stand- and canopy-level factors such as light attenuation, leaf morphology, soil water limitations, and vertical ozone gradients.

The resulting model was applied to 64 locations across the northeastern United States using ambient ozone data from 1987 to 1992. Predicted declines in annual net primary production ranged from 3 to $16 \%$ with greatest reductions in southern portions of the region where ozone levels were highest, and on soils with high water-holding capacity where drought stress was absent. Reductions in predicted wood growth were slightly greater (3$22 \%$ ) because wood is a lower carbon allocation priority in the model than leaf and root growth. Interannual variation in predicted ozone effects was small due to concurrent fluctuations in ozone and climate. Periods of high ozone often coincided with hot, dry weather conditions, causing reduced stomatal conductance and ozone uptake. Within-canopy ozone concentration gradients had little effect on predicted growth reductions because concentrations remained high through upper canopy layers where net carbon assimilation and ozone uptake were greatest.

Sensitivity analyses indicate a trade-off between model sensitivity to available soil water and foliar nitrogen and demonstrate uncertainties regarding several assumptions used in the model. Uncertainties surrounding ozone effects on stomatal function and plant water use efficiency were found to have important implications on current predictions. Field measurements of ozone effects on mature forests will be needed before the accuracy of model predictions can be fully assessed.
\end{abstract}

Key words: air pollution; drought stress; foliar nitrogen; forest canopy; forest productivity; modeling; net primary production; ozone; photosynthesis; stomatal conductance; tree growth.

\section{INTRODUCTION}

Tropospheric ozone is one of the most pervasive and detrimental air pollutants known to affect forest vegetation. Repeated studies have demonstrated that ozone concentrations commonly observed in polluted air masses can have substantial impacts on plant function. Despite regulatory efforts aimed at controlling emissions of the precursor compounds (nitrogen oxides and volatile organics), ozone levels have continually exceeded national ambient air quality standards (NAAQS) across much of the United States and are expected to increase into the foreseeable future (National Research Council 1992).

A large body of research has documented the mech-

Manuscript received 20 November 1996; revised 17 March 1997; accepted 7 April 1997. anisms by which ozone affects plants. A number of reviews are available for comprehensive discussions of these mechanisms (Guderian et al. 1985, Heck et al. 1988, Pye 1988), but, in general, observed responses can be viewed as those involving either the acquisition or allocation of carbon. At the physiological level, the most pronounced effect of ozone on plant carbon gain is a reduction in net photosynthesis resulting from the oxidation of pigments and photosynthetic enzymes (Guderian et al. 1985, Reich and Amundson 1985, Pell et al. 1992, Tjoelker et al. 1995). Because injury occurs at the leaf interior, factors affecting leaf gas exchange rates are important in determining plant response to a given level of external exposure (Reich 1987, Taylor and Hanson 1992, Winner 1994). Species with high gas exchange rates, such as early-successional hardwoods, exhibit the greatest growth reductions, while slow- 
growing species such as spruce are less affected (e.g., Reich and Amundson 1985, Wang et al. 1986, Skarby et al. 1995).

Because plant allocation patterns have evolved towards optimized use of available carbon to meet the requirements of a particular growth strategy, any change in $\mathrm{C}$ fixation is likely to affect subsequent partitioning into different plant tissues (Mooney and Winner 1991). In seedlings, ozone has been observed to induce reductions in root/shoot ratios as allocation shifts towards the maintenance or replacement of ozone-damaged foliage at the expense of root growth (Hogsett et al. 1985, Laurence et al. 1994, McLaughlin et al. 1994, Pell et al. 1994)

Although ozone damage mechanisms have been well studied at the seedling and leaf level, it is still difficult to assess impacts on mature forests across real landscapes. Direct application of seedling-level results is problematic for several reasons. Factors such as light availability, leaf morphology, and ozone concentrations all vary within a forest canopy. This complicates estimation of pollutant uptake via their effects on stomatal conductance and ozone exposure levels (Pye 1988). Additional uncertainty stems from differences in growth patterns and resource constraints of seedlings vs. mature trees (Pye 1988, Edwards et al. 1994, Fredericksen et al. 1994). Seedlings are at a flexible ontogenetic stage, are often grown in pots with ample water and nutrients, and therefore have more dynamic carbon economies than mature trees, which are less allocationally plastic and must compete for light, water, and other resources.

One method of addressing these scaling issues is to incorporate ozone-response relationships into process models that simulate tree growth and ecosystem function. Several studies have used models to simulate the plant-level response of conifers (Laurence et al. 1993, Chen et al. 1994, Weinstein and Yanai 1994), but the approach has not been applied to mature hardwood forests under ambient field conditions. The purpose of this study was to integrate physiological ozone response data into a forest ecosystem model known as PnET-II (Aber et al. 1995, 1996) in order to simulate the effects of ozone on mature hardwood forests in the northeastern United States. PnET-II is a physiologically based model that was designed to capture important ecosystem processes while retaining enough simplicity to be run on the types of data available across large regions. Our approach was to characterize leaflevel ozone effects on carbon fixation and add the resulting algorithms to individual canopy layers within the model. By combining this with measured canopy ozone gradients, ozone effects are assessed for each canopy layer as influenced by variation in light, water, and ozone exposure

We applied the model using ambient ozone data from 64 locations across the northeastern United States, a region dominated by hardwood forests that is chroni- cally impacted by ozone and other urban and industrial air pollutants. Predictions are given for all 64 sites using mean climate and ozone from the period of 1987 1992 and for a subset of 12 of these sites using monthly climate and ozone for the same time period. In addition to estimating ozone effects on regional forest growth, questions we sought to address were (1) how do predictions vary with respect to site moisture status, (2) what are the effects of year-to-year fluctuations in climate, and (3) what are the potential consequences of assumptions used in the model.

\section{Methods}

\section{The PnET-II model}

PnET-II is a monthly time-step model of forest carbon and water balances that is built on several generalized relationships. Maximum leaf photosynthetic rate $\left(A_{\max }\right)$ is determined as a linear function of foliar nitrogen content, following a strong relationship between the two across species from diverse ecosystems (Field and Mooney 1986, Reich et al. 1995). Stomatal conductance is related to the actual rate of net photosynthesis, making plant water use efficiency an inverse function of the atmospheric vapor pressure deficit (Sinclair et al. 1984, Baldocci et al. 1987). This allows transpiration to be determined from canopy photosynthesis, providing a link between forest carbon uptake and site water balances.

These relationships are used in constructing a multilayered forest canopy in which available light and specific leaf mass (SLM) decline with depth through the canopy. Light attenuation is based on the BeersLambert exponential decay equation $\left(y=e^{-k \times \text { LAI }}\right.$, where $\mathrm{LAI}=$ leaf area index) with a light extinction coefficient of 0.58 for hardwood forests. Changes in SLM through the canopy are based on Ellsworth and Reich (1993), resulting in a gradient of area-based but not mass-based foliar nitrogen concentration (Ellsworth and Reich 1993). This allows interaction between mass-based $A_{\max }$ and area-based light interception within each canopy layer. These equations are used in a numerical integration over 50 canopy layers in order to capture the effect of gradual light attenuation on photosynthesis over the entire canopy. Photosynthetic response curves for light and temperature were derived by Aber and Federer (1992). The photosynthetic response to vapor pressure deficit (VPD) is based on a power function described by Aber et al. (1996). Actual evapotranspiration and moisture stress are calculated as functions of plant water demand and available soil water, which is determined using equations from Federer and Lash (1978).

Leaf production is initiated as a function of cumulative growing-degree-days and is drawn from bud carbon reserves accumulated during the previous year. Maximum foliar biomass is a function of available light, foliar N, and SLM, but is also affected in a given 
year by stress-induced reductions in foliar mass during the previous year (Aber et al. 1995). This has the effect of minimizing intra-annual variation in leaf area display due, for instance, to midsummer drought. Root growth is based on the linear relationship between aboveground litter production and root allocation determined by Raich and Nadelhoffer (1989). This relationship produces a decrease in proportional belowground allocation with increasing allocation to foliage. Annual allocation to wood is determined as a fraction of the remaining plant $\mathrm{C}$ pool after production of foliage and roots. The only constraint on wood production ensures that the ratio of wood $\mathrm{C}$ to bud $\mathrm{C}$ does not fall below a critical level, specified as a parameter in the model. For hardwoods, this parameter is set to 1.5 and serves to prevent foliar growth in excess of that which can be sustained by production of new xylem tissue each year (Aber et al. 1995). When wood growth falls below this level, carbon is drawn from bud $\mathrm{C}$ until this ratio is maintained. Thus, wood represents the lowest carbon allocation priority and is the most responsive growth compartment to environmental fluctuations.

The model has performed well at predicting wood growth, net primary production, and water runoff at diverse locations across North America (Aber and Federer 1992, Aber et al. 1995), and has also been successfully tested against eddy flux $\mathrm{CO}_{2}$ exchange measurements (Aber et al. 1996).

\section{Ozone response relationships}

Photosynthesis.-Data from the literature demonstrate strong relationships between cumulative ozone exposure and reductions in both net photosynthesis and plant growth (e.g., Guderian et al. 1985, Reich and Amundson 1985, Reich 1987, Pell et al. 1992, Volin et al. 1993, Skarby et al. 1995, Tjoelker et al. 1995). These relationship can vary among and even within species, although much of this variation is related to differences in stomatal conductance (Thorne and Hanson 1972, Reich 1987, Winner 1994). Because conductance is the most important regulator of ozone uptake under a given external concentration (Taylor and Hanson 1992, Munger et al. 1996), this suggests that ozone effects on photosynthesis can be determined largely as a function of ozone uptake to internal leaf surfaces (Reich 1987, Laisk et al. 1989, Taylor and Hanson 1992). This is not to say that other factors are unimportant. Differences in plant sensitivity per unit ozone uptake have also been noted and are likely related to differences in leaf biochemistry or cellular anatomy (Taylor and Hanson 1992). However, when considering the range of species that typically occurs across natural landscapes, these differences appear much smaller proportionally than differences attributed to conductance, and hence uptake. Differences in response per unit uptake also tend to be greater in magnitude between functional groups (e.g., hardwoods vs.

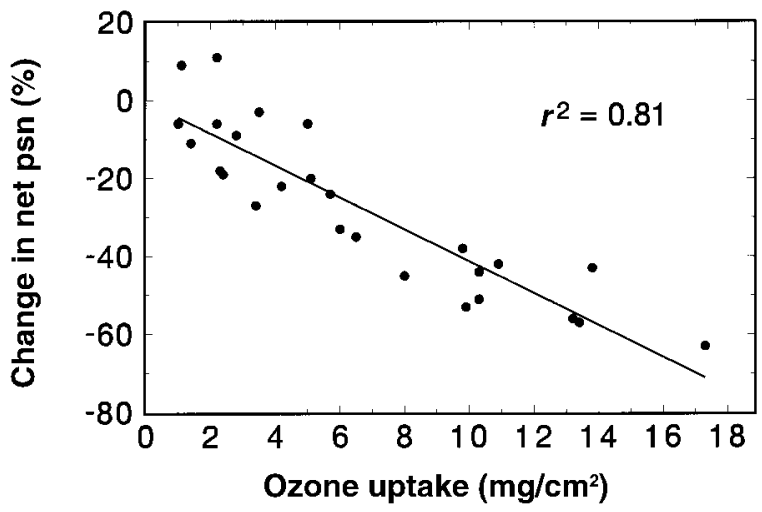

FIG. 1. Percentage reduction in net photosynthesis (psn) in relation to ozone uptake for hardwoods, from Reich (1987) using data from independent studies conducted over periods of several days to several months on a variety of hardwood seedlings.

conifers) where leaf structure and plant growth strategy differ most widely (Reich 1987). If we limit the literature data examined by Reich (1987) to hardwoods, $81 \%$ of the variation in observed photosynthetic response can be explained by cumulative ozone uptake alone (Fig. 1). Given the strength of this relationship and uncertainties surrounding additional sources of variation, examining its implications across natural forested landscapes represents a valuable way to advance current understanding of ozone effects, even while recognizing the limitations of its simplicity.

Although most of the data relating ozone exposure to changes in photosynthesis come from seedlings, several studies conducted on mature trees indicate similar or perhaps greater responses. Tjoelker et al. (1995) obtained a response consistent with that shown in Fig. 1 from mature sugar maple leaves, suggesting that at the leaf level, seedlings and mature trees respond similarly. In contrast, Edwards et al. (1994) compared the photosynthetic responses of mature and seedling red oak trees and found mature trees to exhibit greater reductions than seedlings. This was attributed to differences in seedling vs. mature-tree carbon allocation. Seedlings consistently produced multiple leaf flushes and exhibited indeterminate stem growth, whereas mature trees produced only a single growth flush each spring. Although changes in seedling photosynthesis were not reported with respect to leaf age or ozone uptake, indeterminate growth patterns can result in lower responses at the plant level because only a fraction of the leaves produced are exposed to ozone for the entire growing season. Such differences in ozone exposure have been demonstrated by Fredericksen et al. (1994) between open-grown seedling and mature black cherry trees. Although seedlings exhibited greater instantaneous rates of ozone uptake than mature trees, their indeterminate shoot growth resulted in reduced average exposure times and subsequently lower cumulative uptake. 
Indeterminate growth can also lead to lower reductions or even increases in whole-plant photosynthesis by allowing midseason adjustments in allocation of carbon and nutrients. Pell et al. (1994) reviewed several studies where increased photosynthesis was observed in younger foliage of free-growing seedlings after older foliage suffered damage from ozone. This compensation mechanism was less important for species with a limited number of growth flushes and is not expected to occur in mature, closed-canopy trees, which produce all of their foliage at the beginning of the growing season and typically never flush again.

These results suggest that differences between seedling and mature-tree allocation patterns can cause differences in ozone response at the plant level, but do not indicate differences in the relationship between cumulative ozone uptake and net photosynthesis among individual leaves. This underscores the importance of distinguishing between leaf- and plant-level responses in extrapolating seedling response data to mature, fieldgrown trees.

For the present study, we pooled data from Fig. 1 (Reich 1987) and Tjoelker et al. (1995) in order to derive a leaf-level ozone response equation for broadleaved deciduous species that could be incorporated into the PnET-II model. To minimize differences caused by seedling vs. mature-tree allocation patterns, the data were summarized on an individual leaf basis using initial growth flush foliage where possible. Thus, the response of each leaf could be related to cumulative ozone uptake calculated over its own life-span. From the resulting data set we obtained the following response equation:

$$
d \mathrm{O}_{3}=1-\left(\left[2.6 \times 10^{-6}\right] \times g \times \mathrm{D} 40\right)
$$

where $d \mathrm{O}_{3}$ is the ratio of ozone-exposed to control photosynthesis, $2.6 \times 10^{-6}$ is an empirically derived ozone response coefficient, $g$ is mean stomatal conductance to water vapor (in millimeters per second), and D40 is the cumulative ozone dose above a threshold concentration of $40 \mathrm{nmol} / \mathrm{mol}$. The diffusivity ratio of ozone to water vapor is not explicitly used in the equation, but as a constant is accounted for by the calculated ozone response coefficient. The D40 dose is accumulated over the entire growing season and is calculated as the sum of all hourly values $>40 \mathrm{nmol} / \mathrm{mol}$ after subtracting 40 from each. We use this threshold because $40 \mathrm{nmol} / \mathrm{mol}$ is the approximate level at which negative impacts begin to appear in the pooled data set and because lower concentrations become confused with natural background levels. Other studies have also found $40 \mathrm{nmol} / \mathrm{mol}$ to be the level at which growth effects begin to occur (Fuhrer 1994, McLaughlin and Downing 1995), and this was the threshold used by Weinstein and Yanai (1994) in modeling ozone effects on red spruce and ponderosa pine.

Stomatal conductance.-Stomatal conductance is calculated as a linear function of net photosynthesis, based on the strong relationship $\left(r^{2}=0.93\right)$ derived by Aber and Federer (1992) using data from the literature (Aubuchon et al. 1978, Hinckley et al. 1978, Abrams et al. 1990, Amthor et al. 1990):

$$
g=-0.3133+0.8126(\text { NetPsn })
$$

where $g$ is stomatal conductance to water vapor (in millimeters per second) and NetPsn is the actual rate of net photosynthesis (in micromoles per square meter per second).

Given this relationship, conductance should be expected to decline along with photosynthesis in response to ozone. Among data reported in the literature, the effect of ozone on conductance is reasonably consistent, although there is some indication that the response varies with the light environment of treated foliage (Reich and Lassoie 1984, Volin et al. 1993). In both of these cases, sunlit leaves showed slight declines in conductance with ozone treatment, while shaded leaves showed no change or moderate increases. In other studies, declines in conductance were observed in both sun and shade leaves (Tjoelker et al. 1995), and in sun leaves where only well-lit foliage was examined (Pell et al. 1992). In most cases, changes in conductance were small and occurred after the photosynthetic response. We incorporated this effect into the model by including a simple feedback whereby a reduction in photosynthesis for a given month causes a proportional reduction in conductance during the following month. This was done to reproduce the observed lag between declines in photosynthesis and conductance. In the model, it has the effect of reducing subsequent ozone uptake following damage, assuming that photosynthesis and conductance remain coupled. An uncoupling of these two variables would have important implications for interactions between ozone and water stress as discussed in Sensitivity analyses below.

Allocation.-In addition to the leaf-level responses of photosynthesis and conductance, many seedling studies have observed reductions in the ratio of aboveto belowground production following exposure to ozone (e.g., Hogsett et al. 1985, Laurence et al. 1994, McLaughlin et al. 1994, Pell et al. 1994). This is often viewed as a compensation mechanism whereby additional carbon is allocated to the replacement of damaged foliage. This can offset or prevent reductions in photosynthesis at the plant level, but comes at the expense of allocation to other plant tissues. For the present exercise, ozone effects on carbon allocation are not explicitly included in the model, but rather, reductions in carbon uptake are allowed to interact with the model's existing allocation priorities. Because the model allocates preferentially to the canopy and lastly to wood, elevated ozone will result primarily in decreased wood growth and increased proportional allocation to foliage. In light of differences between seedling and mature-tree allocation constraints and available data suggesting that mature trees have a lower capacity for 

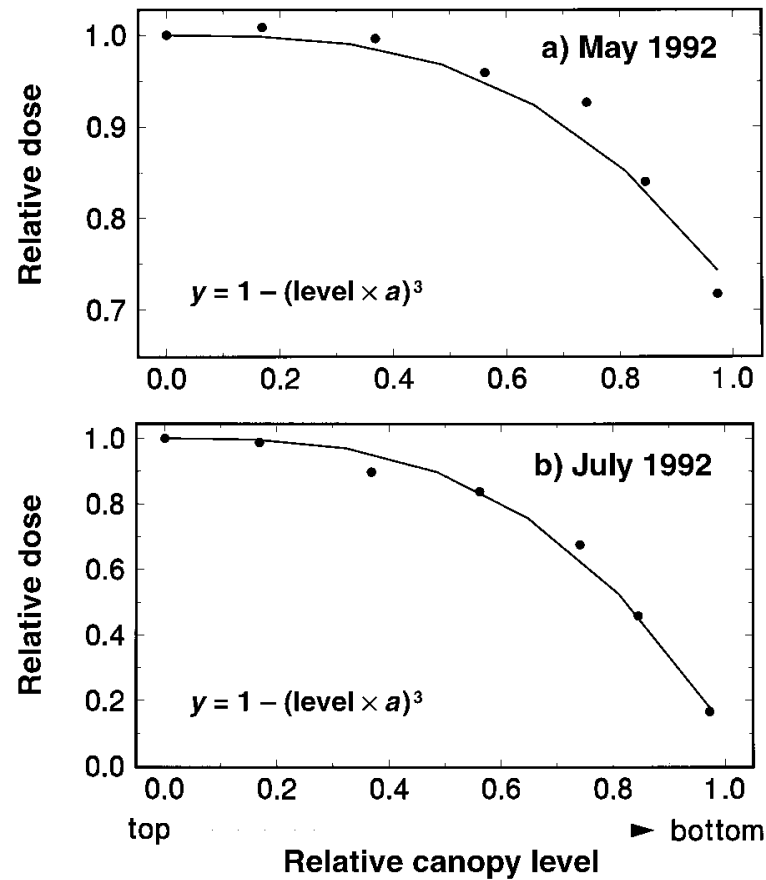

FIG. 2. Ozone dose $>40 \mathrm{nmol} / \mathrm{mol}$ in relation to canopy position at the Harvard Forest in central Massachusetts in (a) May 1992 and (b) July 1992. Both axes have been normalized to a scale of 0-1. Data are from Munger et al. (1996).

compensation (Edwards et al. 1994), we view this as a more reasonable approach than attempting to reproduce the dynamic root/shoot ratio patterns often observed among seedlings and potted plants. Nevertheless, uncertainties in this area are well recognized and should highlight the need for further experimental work on mature forests.

\section{Canopy ozone gradients}

One uncertainty in extrapolating ozone effects to whole forests is the question of how ozone concentrations vary within a forest canopy (Pye 1988). Canopy ozone gradients are expected to result from several factors, but their importance in moderating growth reductions has not been rigorously tested. To address this, we used ozone data from Munger et al. (1996) collected over a 3-yr period at eight positions within a mixedhardwood canopy at the Harvard Forest eddy correlation tower in central Massachusetts. The tower is located in a $24 \mathrm{~m}$ tall hardwood forest that consists mainly of 50-70 yr old red oak and red maple. Hourly ozone concentrations were measured by UV absorbance.

For the present study, we calculated ozone D40 values for each tower position and plotted the resulting patterns for all months of the growing season (Fig. 2). In typical results from May and July 1992, D40 values below the canopy decreased to 72 and $18 \%$ of the abovecanopy values, respectively. These patterns are consistent from month to month, whereby the rate of depletion increases with depth through the canopy. For all years examined, ozone profiles followed seasonal canopy development, becoming established around the time of spring leaf expansion, increasing through midsummer, and declining at the end of the growing season. These trends can be closely approximated by the equation:

$$
d \mathrm{D} 40_{i}=1-(i \times a)^{3}
$$

where $d \mathrm{D} 40_{i}$ is the proportion of the abovecanopy D40 at a given canopy level, $i$ is the normalized canopy level from 0 at the top of the canopy to 1 at the ground, and $a$ is the ozone extinction coefficient, determined for each month (Fig. 2). Table 1 shows monthly values of $a$ along with the corresponding percentage change in $\mathrm{D} 40$ from above to below the canopy.

Munger et al. (1996) determined that ozone deposition at Harvard Forest is related to stomatal conductance of water vapor, indicating stomatal uptake as the dominant deposition pathway. Other factors expected to influence canopy ozone gradients are canopy resistance to vertical mixing, ozone deposition directly onto leaf surfaces, and scavenging by reactive gases such as volatile organic compounds and nitrogen oxides. Because most of these are influenced by canopy leaf area, we compared the observed monthly ozone extinction coefficients with monthly leaf area index. In absence of measured LAI data for this time period, we used values generated by a daily version of PnET, parameterized for the Harvard Forest site using measured canopy biomass and validated against eddy correlation

TABLE 1. Solutions to Eq. 2, showing canopy gradients of ozone dose (D40) at Harvard Forest from 1991 to 1993: $a$ represents the ozone extinction coefficient from Eq. $3, r^{2}$ is the nonlinear least-squares coefficient of determination, and \% change is the percentage reduction in D40 from above to below the canopy. Data were not available for October 1992.

\begin{tabular}{|c|c|c|c|c|c|c|c|c|c|}
\hline \multirow[b]{2}{*}{ Month } & \multicolumn{3}{|c|}{1991} & \multicolumn{3}{|c|}{1992} & \multicolumn{3}{|c|}{1993} \\
\hline & $a$ & $r^{2}$ & $\begin{array}{c}\% \\
\text { change }\end{array}$ & $a$ & $r^{2}$ & $\begin{array}{c}\% \\
\text { change }\end{array}$ & $a$ & $r^{2}$ & $\begin{array}{c}\% \\
\text { change }\end{array}$ \\
\hline May & 0.67 & 0.98 & 30 & 0.65 & 0.96 & 28 & 0.73 & 0.98 & 36 \\
\hline June & 0.90 & 0.96 & 75 & 0.79 & 0.95 & 51 & 0.83 & 0.98 & 56 \\
\hline July & 1.00 & 0.97 & 91 & 0.96 & 0.99 & 82 & 0.81 & 0.98 & 51 \\
\hline August & 0.96 & 0.97 & 83 & 0.90 & 0.95 & 71 & 0.92 & 0.90 & 70 \\
\hline September & 1.05 & 0.96 & 99 & 0.92 & 0.98 & 74 & 0.85 & 0.96 & 59 \\
\hline October & 0.87 & 0.98 & 64 & $\ldots$ & $\ldots$ & $\ldots$ & 0.79 & 0.84 & 58 \\
\hline
\end{tabular}




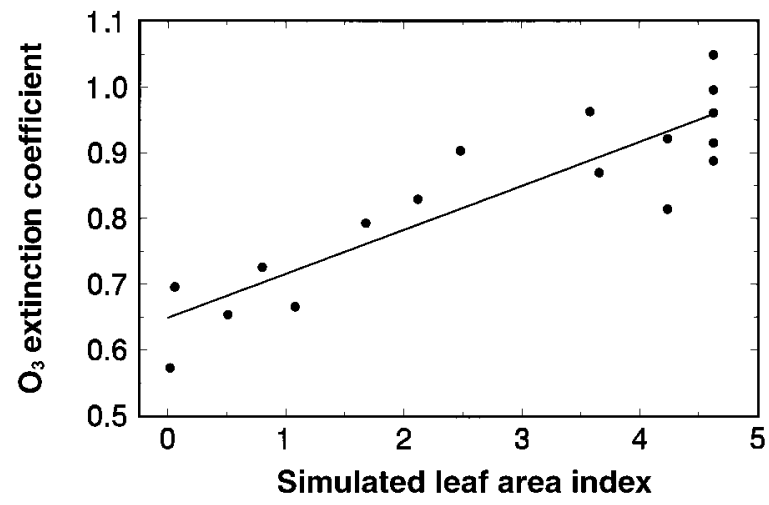

FIG. 3. Canopy ozone gradient coefficient ( $a$ from Eq. 2) in relation to monthly leaf area index (LAI data are from Aber et al. 1996). Higher values of $a$ correspond to steeper canopy ozone gradients.

$\mathrm{CO}_{2}$ flux measurements obtained at the tower (Aber et al. 1996). This comparison showed LAI to be a strong predictor of vertical ozone depletion $\left(r^{2}=0.80\right.$; Fig. 3 ) suggesting that canopy structure plays an important role in vertical ozone gradients. To include this in the model, predicted monthly LAI is used to calculate the ozone extinction coefficient (Eq. 3), which then determines the relative D40 for each canopy layer. We cannot presently evaluate the extent to which this relationship might differ in other forests. However, we expect differences to be small for other closed-canopy hardwood forests within the northeast, where canopy structure and atmospheric conditions are similar to those at Harvard Forest. Greater differences may be anticipated in other regions or for other forest types where these factors differ more dramatically.

\section{Interactions between ozone and drought}

For each canopy layer, the model calculates photosynthesis with and without ozone in order to determine the potential, integrated ozone effect for the whole canopy. This is necessary in order to allow interaction with drought stress, which is calculated once and applied to the entire canopy rather than being explicitly included in each canopy layer. After the calculation of potential photosynthesis over all canopy layers, the model's water balance routine determines potential transpiration and performs a comparison with the amount of available soil moisture. If soil moisture is not adequate to meet the transpirational demand, water stress ensues and canopy photosynthesis is reduced.

Because the primary physiological response to water limitation is stomatal closure and ozone effects are calculated as a function of stomatal conductance, the potential (predrought) whole-canopy ozone effect is reduced each month in proportion to the degree of water stress experienced during that month. For example, if water stress causes a $20 \%$ reduction in potential photosynthesis and the potential ozone effect, integrated across all leaf layers, is also a $20 \%$ reduction, the final ozone effect is reduced by a factor of 0.8 to become $16 \%\left(d \mathrm{O}_{3}=0.84\right)$. This assumes that ozone has no negative impact on the ability of stomates to regulate transpiration. As such, the primary water-ozone interaction is for water limitation to reduce ozone uptake, a response that has been observed under experimental conditions (Dobson et al. 1990, Fredericksen et al. 1994) and has been included in model analyses for ponderosa pine seedlings (Chen et al. 1994). Some studies have suggested that under certain conditions, usually after intense and prolonged ozone exposure, stomatal function can become impaired (Reich and Lassoie 1984, Tjoelker et al. 1995). If this occurs, waterozone interactions would become more complicated and may include situations where ozone exacerbates drought stress via reductions in water use efficiency. Although this is an area that warrants further investigation, there is presently too little information to include such a feedback in the model.

\section{Model application}

A simplified flow diagram of the PnET- $\mathrm{O}_{3}$ model is shown in Fig. 4. For the prediction of ozone effects on forest growth, Eq. 1 was incorporated into the model's photosynthesis routine for each individual canopy layer. For each layer, leaf conductance is determined as a function of net photosynthesis, and is thus affected by available light at that layer, foliar nitrogen content, temperature, and vapor pressure deficit. Monthly D40 values are estimated for each layer by combining ambient ozone concentrations with the calculated ozone depletion profiles. Monthly ozone effects are determined from May through October and are based on cumulative exposure over the entire season for each canopy layer.

Ozone data.-Ambient ozone data for the northeastern United States were obtained from the U.S. Environmental Protection Agency's (EPA) Aerometric Information Retrieval System for the period of 19871992. For each collection station, we used raw, hourly concentrations to calculate monthly D40 values and long-term monthly means. We only considered measurements from between 0700 and 1900 to exclude unusually high nighttime concentrations. To minimize error caused by missing data, we imposed a $75 \%$ completeness criterion on each month within the data record. For each station, any month containing $<75 \%$ of the expected number of observations was omitted from the calculation of long-term monthly means. Months with between 75 and $100 \%$ data completeness were corrected for missing periods by dividing the measured D40 value by the proportion of data completeness. This assumes that the distribution of concentrations within the missing period was the same as that of the observed data. The majority of sites where this correction was performed had $<10 \%$ missing data. After data screening was complete, we eliminated sites that contained less than a $3-y r$ record. The resulting data set included 64 sites (from an initial total of 


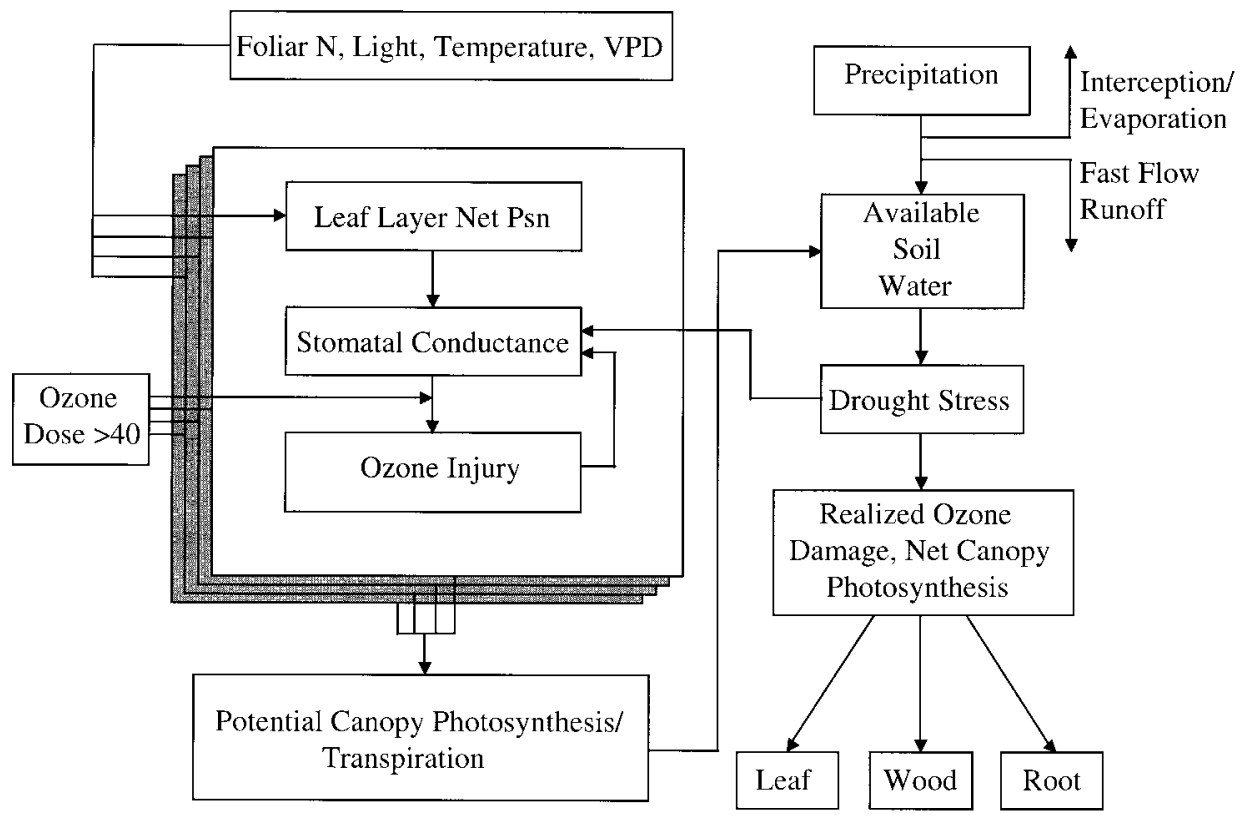

FIG. 4. Simplified flow diagram of processes included in the PnET-ozone response model $\left(\mathrm{PnET}-\mathrm{O}_{3}\right)$. VPD refers to the atmospheric vapor pressure deficit, and Dose $>40$ is the cumulative ozone dose above a threshold concentration of $40 \mathrm{nmol} /$ mol, calculated over the entire growing season.

$\sim 100$ ), each with 3-6 yr of data from the period of 1987-1992 (Fig. 5). In computing long-term mean D40 values, some bias among sites may result from differences in the years for which data were available.

Model application using mean climate and ozone.Climate inputs required to run the model are monthly averages of maximum and minimum daily temperature, solar radiation, and vapor pressure deficit along with total monthly precipitation. For model application un- der average climate and ozone at all 64 ozone-monitoring sites, we used long-term mean climate values calculated for each site by a statistical climate model developed for the northeast region (Ollinger et al. 1995). We used a foliar nitrogen concentration of $2.2 \%$, based on values measured among a variety of hardwood species at the Harvard Forest (Martin and Aber 1996). To evaluate the effects of site moisture conditions, we ran the model under a range of soil water-holding ca-

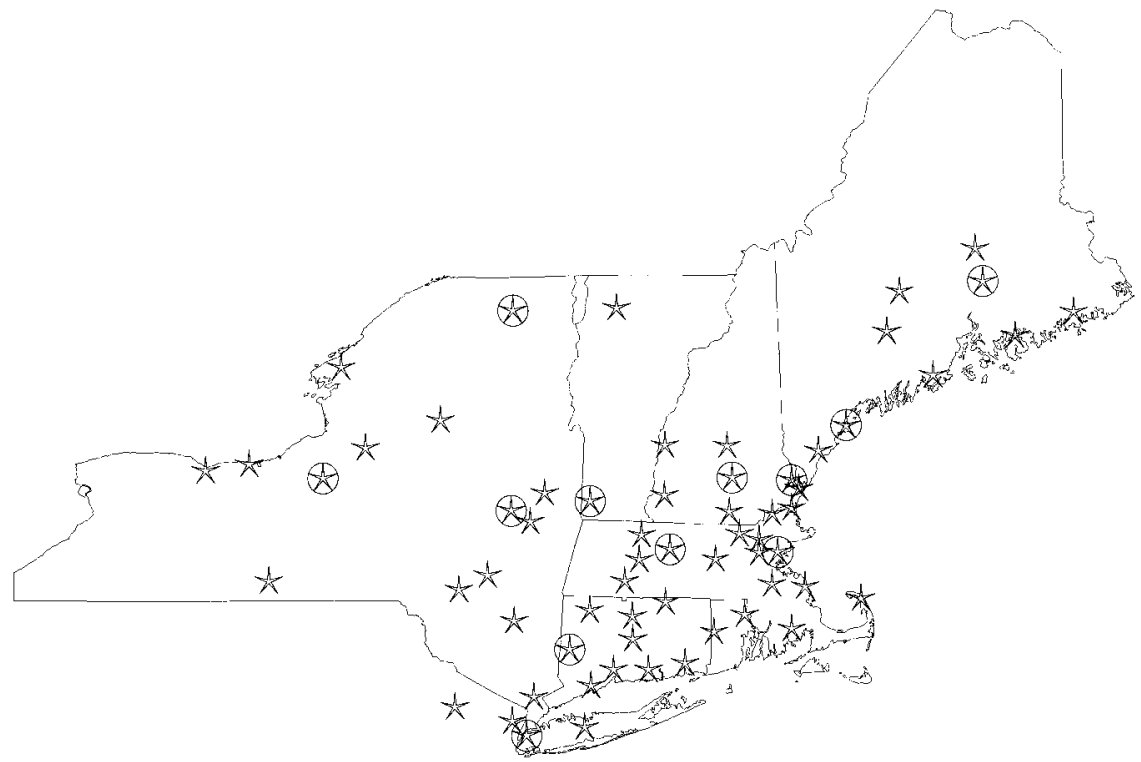

FIG. 5. Locations of EPA ozone-monitoring stations used for this study. Circled stations represent sites where monthly climate and ozone data were used in addition to long-term mean values. 
TABLE 2. Locations of 12 ozone monitoring stations and associated weather stations used for analysis of temporal variation in predicted growth impacts. Stations marked with an asterisk represent rural sites located near the town or city listed. All stations include data from the entire 1987-1992 period.

\begin{tabular}{lccl}
\hline \hline \multicolumn{1}{c}{ Station name } & $\begin{array}{c}\text { Latitude } \\
\left({ }^{\circ}\right)\end{array}$ & $\begin{array}{c}\text { Longitude } \\
\left({ }^{\circ}\right)\end{array}$ & \multicolumn{1}{c}{ Weather station } \\
\hline New York City, New York & 40.68 & 74.01 & New York City, New York \\
Danbury, Connecticut & 41.42 & 73.47 & Shepaug Dam, Connecticut \\
Chelsea, Massachusetts & 42.44 & 71.06 & Boston, Massachusetts \\
Ware, Massachusetts & 42.33 & 72.35 & Amherst, Massachusetts \\
Cape Elizabeth, Maine & 43.62 & 70.25 & Portland, Maine \\
Bangor, Maine* & 44.70 & 68.86 & Bangor, Maine \\
Manchester, New Hampshire & 43.03 & 71.47 & Nashua, New Hampshire \\
Portsmouth, New Hampshire & 43.08 & 71.77 & Durham, New Hampshire \\
Syracuse, New York* & 43.11 & 76.16 & Syracuse, New York \\
Lake Placid, New York* & 44.37 & 73.95 & Lake Placid, New York \\
Schenectady, New York & 42.81 & 73.97 & Albany, New York \\
Bennington, Vermont & 42.90 & 73.27 & Readsboro, Vermont \\
\hline
\end{tabular}

pacity values (WHC) representing optimal to severely limited soil water retention. We chose this approach instead of using fixed values for each site because soil properties vary over much finer spatial scales than ozone. Hence, ozone levels encountered in the area of each monitoring station may interact with a wide range of soil moisture conditions over the local landscape. The WHC values used ranged from $2 \mathrm{~cm}$, representing a coarse sand with $50 \%$ large fragments, to $36 \mathrm{~cm}$, representing a clay loam with no large fragments. The intermediate value of $12 \mathrm{~cm}$ is considered most common for the northeast region, representing a typical glacial till soil with $25 \%$ large fragments (Federer 1982).

We performed an additional set of analyses in order to test the model's sensitivity to canopy ozone gradients (Eq. 3). For this, the model was rerun at all 64 sites with ozone held constant through all canopy layers. Canopy gradient effects were assessed by comparing declines in annual net primary production (NPP) with intact gradients vs. those after gradients were removed.

Model application using actual monthly climate and ozone.-To examine temporal interactions between ozone and climate and to determine year-to-year variability in predicted ozone effects, we selected a subset of 12 sites for analysis using actual monthly ozone and climate values (Fig. 5, Table 2). Site selection was aimed at attaining even distribution across the study region, but was constrained to stations having ozone records for the entire 1987-1992 period with minimal missing values. Monthly climate data were obtained from the Northeast Regional Climatic Data Center for weather stations nearest to the ozone-monitoring stations (Table 2). The weather stations recorded maximum and minimum daily temperature and precipitation, but not solar radiation. Instead, we used values calculated by the statistical climate model (Ollinger et al. 1995) for each location. Soil WHC was held at 12 $\mathrm{cm}$ for all sites. For each site, initial conditions for forest structure and productivity were determined by allowing the model to reach equilibrium under long- term mean climate and ozone. From these initial conditions, predictions were generated using monthly climate and ozone data from 1987 through 1992.

\section{Sensitivity analyses}

Sensitivity analyses provide a means of testing the importance of assumptions made in developing and parameterizing a model. Many parameters and algorithms used in PnET-II have been tested previously (Aber and Federer 1992, Aber et al. 1995, 1996) and will not be reexamined here. However, several assumptions used in adding ozone effects to the model warrant further attention as they have potentially important implications on predicted forest response. Those assumptions are: (1) the model's allocation priorities assume that mature trees value foliar production over other plant compartments and that decreases in carbon gain are taken from wood growth over leaf and root growth; (2) in our treatment of interactions among ozone, conductance, and water stress, we assume that the ability of stomates to regulate transpiration is not hampered by ozone.

To test the effects of assumption 1, we altered the carbon allocation routine such that ozone effects on photosynthesis were distributed more evenly across all growth compartments. This was done by decreasing allocation of available $\mathrm{C}$ to buds for next year's foliage in proportion to the decrease in this year's carbon gain. We labeled this the BudC effect. Testing assumption 2 required changes at several places in the model. First, if stomatal function becomes impaired, photosynthesis and conductance may gradually become uncoupled, such that conductance no longer down-regulates with photosynthesis. Second, an uncoupling of these variables could cause a decrease in plant water use efficiency (WUE). We included these effects in the model based on the results of Tjoelker et al. (1995) in which the relationship between photosynthesis and conductance remained intact through the initial phase of a $2 \times$ ozone fumigation experiment, but began to break down during later stages of treatment. Using approximate 

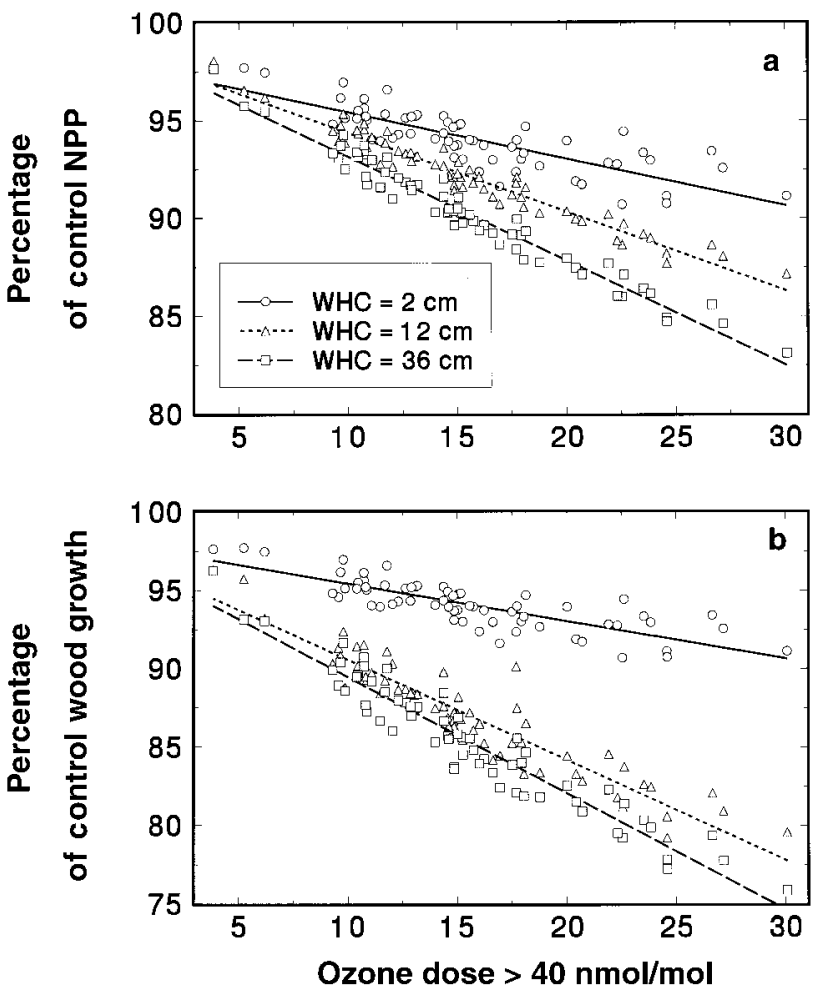

FIG. 6. Predicted change in (a) mean annual NPP (net primary production) and (b) mean annual wood production at 64 sites across the study region in response to mean ozone levels from 1987 to 1992. Predictions are shown for three levels of soil water-holding capacity (WHC) to show the change in response from well-watered (WHC $=36$ ) to severely droughtstressed $(\mathrm{WHC}=2)$ conditions.

dose values from Tjoelker et al. (1995), the down-regulation of conductance with photosynthesis is maintained in the model up to a threshold D40 of $11 \mathrm{ppm} \cdot \mathrm{h}$. Between 11 and $41 \mathrm{ppm} \cdot \mathrm{h}$, conductance increases linearly until reaching pre-ozone levels. At the same time, WUE is scaled downward in proportion to ozone effects on total photosynthesis. These changes produce a gradual decline in stomatal function and have the effect of increasing ozone uptake and canopy transpiration. We labeled this the WUE effect.

Previous sensitivity analyses have suggested that foliar nitrogen concentration (FolN) and soil water-holding capacity (WHC) are critical parameters in determining rates of photosynthesis and growth in northeastern hardwoods. To examine interactions between these parameters and the above assumptions, we used a randomized, Monte Carlo approach. First, the model was run for the 64 ozone monitoring sites using mean ambient ozone and randomized inputs for FolN and WHC. Values for FolN ranged from 1.8 to $2.6 \mathrm{mg} / \mathrm{g}$, the approximate range that occurs among northern hardwoods. Soil WHC ranged from 2 to $36 \mathrm{~cm}$. The model was run 10 times for each site for a total of 640 ozone-effect predictions under a range of possible WHC and FolN combinations. This process was then repeated using each scenario of altered model assumptions. The resulting predictions were used to relate re- gional mean ozone effects to variation in WHC and FolN under each model scenario. This approach was used in order to detect nonlinear interactions that may be missed by single factorial analyses.

\section{RESUlts AND Discussion}

\section{Mean climate and ozone}

Results of model runs using mean climate and ozone indicate decreases in annual net primary production (NPP) of from 3 to $16 \%$ as a result of mean ozone levels from 1987 to 1992 (Fig. 6a) with greatest reductions in southern New York and southern New England where ozone levels and canopy conductance were greatest. The predicted decrease was weakly, but negatively correlated with latitude, following a trend of decreasing ozone from south to north across the region. Predictions varied substantially across the range of soil WHC values $(2-36 \mathrm{~cm})$, with smaller growth reductions occurring on drier sites where lower rates of conductance limited ozone uptake by foliage.

At $\mathrm{WHC}=36 \mathrm{~cm}$, water limitations on NPP and wood production were eliminated for all sites, so these values can be used as a reference in estimating drought effects resulting from other soil moisture conditions (Table 3). Under all but the two wettest conditions, water limitation caused greater declines in growth than 
TABLE 3. Predicted net primary production (NPP) and wood growth with and without ozone effects at five levels of soil water-holding capacity $(\mathrm{cm})$. Values shown are means and standard deviations from all 64 study sites.

\begin{tabular}{|c|c|c|c|c|c|c|c|c|c|c|c|c|}
\hline \multirow[b]{3}{*}{ WHC } & \multicolumn{6}{|c|}{$\mathrm{NPP}\left(\mathrm{g} \cdot \mathrm{m}^{-2} \cdot \mathrm{yr}^{-1}\right)$} & \multicolumn{6}{|c|}{ Wood growth $\left(\mathrm{g} \cdot \mathrm{m}^{-2} \cdot \mathrm{yr}^{-1}\right)$} \\
\hline & \multicolumn{2}{|c|}{ Control } & \multicolumn{2}{|c|}{ Ozone } & \multicolumn{2}{|c|}{$\%$ reduction } & \multicolumn{2}{|c|}{ Control } & \multicolumn{2}{|c|}{ Ozone } & \multicolumn{2}{|c|}{$\%$ reduction } \\
\hline & $\bar{X}$ & SD & $\bar{X}$ & SD & $\bar{X}$ & SD & $\bar{X}$ & SD & $\bar{X}$ & SD & $\bar{X}$ & SD \\
\hline 2 & 723 & 37.1 & 682 & 35.4 & 5.7 & 1.4 & 372 & 19.1 & 351 & 18.2 & 5.6 & 1.4 \\
\hline 6 & 1136 & 70.9 & 1054 & 56.2 & 7.1 & 1.9 & 610 & 61.1 & 546 & 34.7 & 10.1 & 4.4 \\
\hline 12 & 1354 & 80.3 & 1254 & 66.6 & 7.4 & 1.8 & 792 & 89.5 & 694 & 70.7 & 12.2 & 3.1 \\
\hline 24 & 1732 & 72.0 & 1584 & 59.7 & 8.5 & 2.2 & 1124 & 77.6 & 976 & 63.5 & 13.1 & 3.2 \\
\hline 36 & 1840 & 85.7 & 1672 & 65.7 & 9.1 & 2.4 & 1228 & 93.1 & 1060 & 71.6 & 13.6 & 3.4 \\
\hline
\end{tabular}

did ozone. At $\mathrm{WHC}=12 \mathrm{~cm}$, representing a typical northeastern glacial till, ozone-induced declines in NPP averaged $81 \%$ of those predicted at $\mathrm{WHC}=36$. At $\mathrm{WHC}=2 \mathrm{~cm}$, an extreme condition for this region, ozone effects averaged $62 \%$ of the drought-free values, despite substantially lower total growth.

Reductions in predicted wood production ranged from 3 to $22 \%$ across all ozone and soil moisture conditions (Fig. 6b). This wider range of variation is a result of the model's carbon allocation priorities, which value leaf and root production above wood growth. With high soil moisture $(\mathrm{WHC}=24-36 \mathrm{~cm}$ ), ozone effects on total plant growth are taken entirely from wood production, with no declines in canopy leaf area or root growth. This occurs because under these conditions, wood growth is high enough that it can be reduced without reaching the critical ratio of wood to foliage production specified in the model. On progressively drier sites, the ratio of wood to foliar production decreases until reaching this critical value. Beyond this point, leaf, wood, and root growth become more tightly coupled, such that further growth declines necessarily affect all three compartments. At WHC $=2 \mathrm{~cm}$, reductions in wood growth accounted for approximately half of the total decline in growth (Table 3 ).

Changes in ozone D40 with depth through the canopy had a minimal effect on predicted growth reductions. Canopy gradients did offset declines in NPP, but by an average of only $0.6 \%$ (maximum $=1.5 \%$ ) with respect to results obtained with canopy gradients removed. Although the gradients produced substantial declines in ozone D40 values through the mid and lower canopy (Fig. 2), ozone in the upper canopy remained high. Because this is where light levels and hence photosynthesis and conductance are greatest, canopy gradients had only a small effect on total canopy ozone uptake. This suggests that unless canopy ozone profiles are substantially different in other forest types or geographic regions, with concentrations falling off sharply through upper canopy layers, vertical ozone gradients are not an important factor in scaling ozone effects to mature forests. These results are consistent with a similar analysis made previously with a simpler canopy photosynthesis model (Reich et al. 1990).

\section{Interactions between climate and ozone}

For the 6-yr period from 1987 to 1992, the only unusual year with respect to ozone was 1988, which had significantly higher levels than all other years except 1991 (Fig. 7a). This was also an anomalous climate year, being one of the warmest on record in the northeast region and having the lowest precipitation of the $6-\mathrm{yr}$ period. Precipitation was more variable than ozone, being consistently greater from 1989 to 1991 than during the other 3 yr (Fig. 7b). Despite these differences in climate and ozone (significant at $P<0.05$ using Scheffé's multiple comparison ANOVA), there were no significant year-to-year differences in predicted growth reductions (Fig. 7c-d). This largely reflects the tendency for high ozone levels to be associated with hot, high-pressure air masses, which often coincide with increased water limitations. Periods of high ozone (e.g., midsummer 1988) were commonly offset by co-occurring reductions in conductance, induced by high temperatures and low precipitation.

Whereas temporal variation in predicted growth reductions was minimal, growth reductions across sites were not only variable, but were more variable than either climate or ozone (Fig. 8; between-site differences determined at $P<0.05$ using Scheffé's multiple comparison ANOVA). This reflects spatial relationships between conductance and ozone that counter the dominant temporal trends. Although high ozone often coincided with low conductance on a temporal basis, high ozone more often coincided with high conductance on a spatial basis. This is at least partially due to the fact that both ozone production and conductance, in general, decrease from south to north within the study region. For ozone, this is driven by the high density of urban areas along southern portions of the region, whereas patterns of conductance tend to follow latitude gradients in temperature and summer precipitation.

Among the 12 intensive study sites, the greatest growth reductions were predicted for New York City and Ware, located in central Massachusetts (Fig. 8), the two sites with the highest ozone levels. Ozone levels were lower in Ware than in New York City, but Ware had higher predicted rates of conductance and thus showed similar growth declines to New York City. 

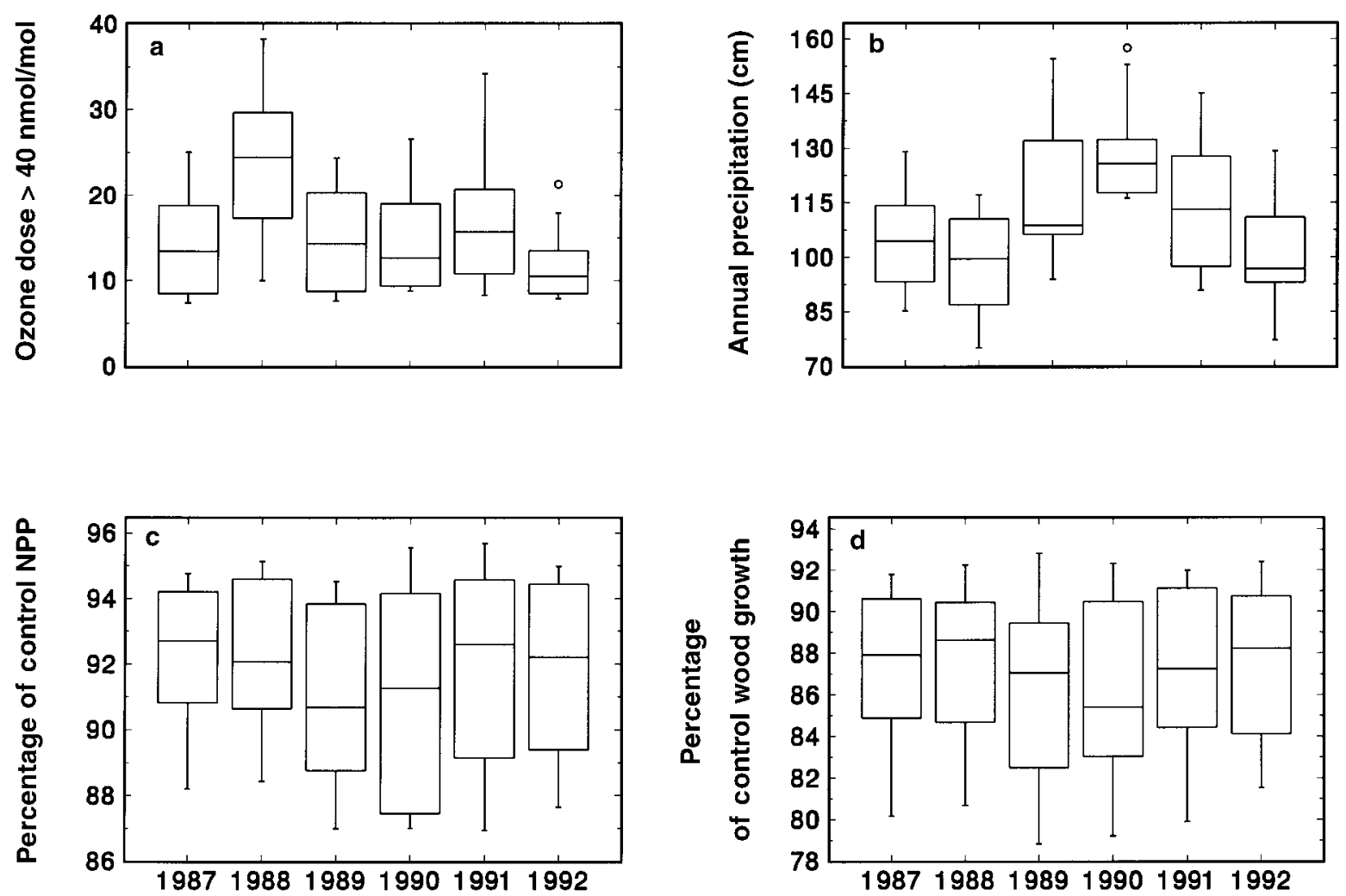

FIG. 7. Distributions of (a) ozone D40, (b) annual precipitation, (c) percentage change in NPP, and (d) percentage change in wood production across the 12 study sites for individual years from 1987 to 1992 . Boxes show median values and quartile ranges. Vertical lines show adjacent values, and circles are outliers.

Although there is a general trend of decreasing ozone concentrations with distance from population centers, a clear distinction between urban and rural areas is difficult to make. Urban areas have higher emissions of the nitrogen oxides and volatile organic compounds that lead to ozone production, but ozone concentrations are often lower in cities than in nearby rural areas because other compounds present in polluted air (e.g., NO) cause a destruction of ozone. Note for example that Chelsea, Massachusetts, an urban area adjacent to Boston, had lower ozone levels than Ware (Massachusetts), Bennington (Vermont), and the site near Syracuse (New York), all located in less densely populated areas (Fig. 8a). Because ozone and its precursor compounds can be transported considerable distances, rural, downwind locations can experience unusually high concentrations. This probably explains the relatively high ozone levels and large growth reductions predicted for Cape Elizabeth, Maine, and the site near Lake Placid, New York, located at an elevation of $\sim 600 \mathrm{~m}$. High concentrations are known to occur at coastal and upper elevation sites because of long-range transport of air that has had little contact with ozone-depleting surfaces. High ozone levels at the rural Bennington, Vermont, site may reflect its location downwind of the Albany, New York, area. Conversely, Schenectady, New York, which is adjacent to, but upwind of Albany, experienced lower ozone levels and lower growth impacts.

\section{Sensitivity analyses}

Randomized sensitivity analyses indicate nonlinear interactions between model sensitivity to FolN and WHC through their effects on photosynthesis, transpiration, water limitations, and ozone uptake. Fig. 9 shows predicted response surfaces indicating the regional mean ozone effect on NPP at various levels of FolN and WHC under three model scenarios. Fig. 9a shows standard PnET-O $\mathrm{O}_{3}$ model results and Fig. 9b, c shows results from scenarios that include ozone effects on allocation (BudC effect) and water use efficiency (WUE effect), respectively. Each surface was generated from 640 model runs (64 sites $\times 10$ runs each) conducted under ambient ozone, but with randomized inputs for FolN and WHC. Values shown represent regional mean ozone injury from all 64 sites.

Using standard model assumptions, model sensitivity to FolN varied with WHC. On dry sites, FolN had little effect on predicted ozone injury because ozone uptake was controlled largely by water availability. On progressively wetter sites, drought stress was diminished and FolN became an increasingly important regulator of photosynthesis and hence uptake. At WHC $=$ $36 \mathrm{~cm}$, mean ozone injury increased from 6.6 to $10.4 \%$ 

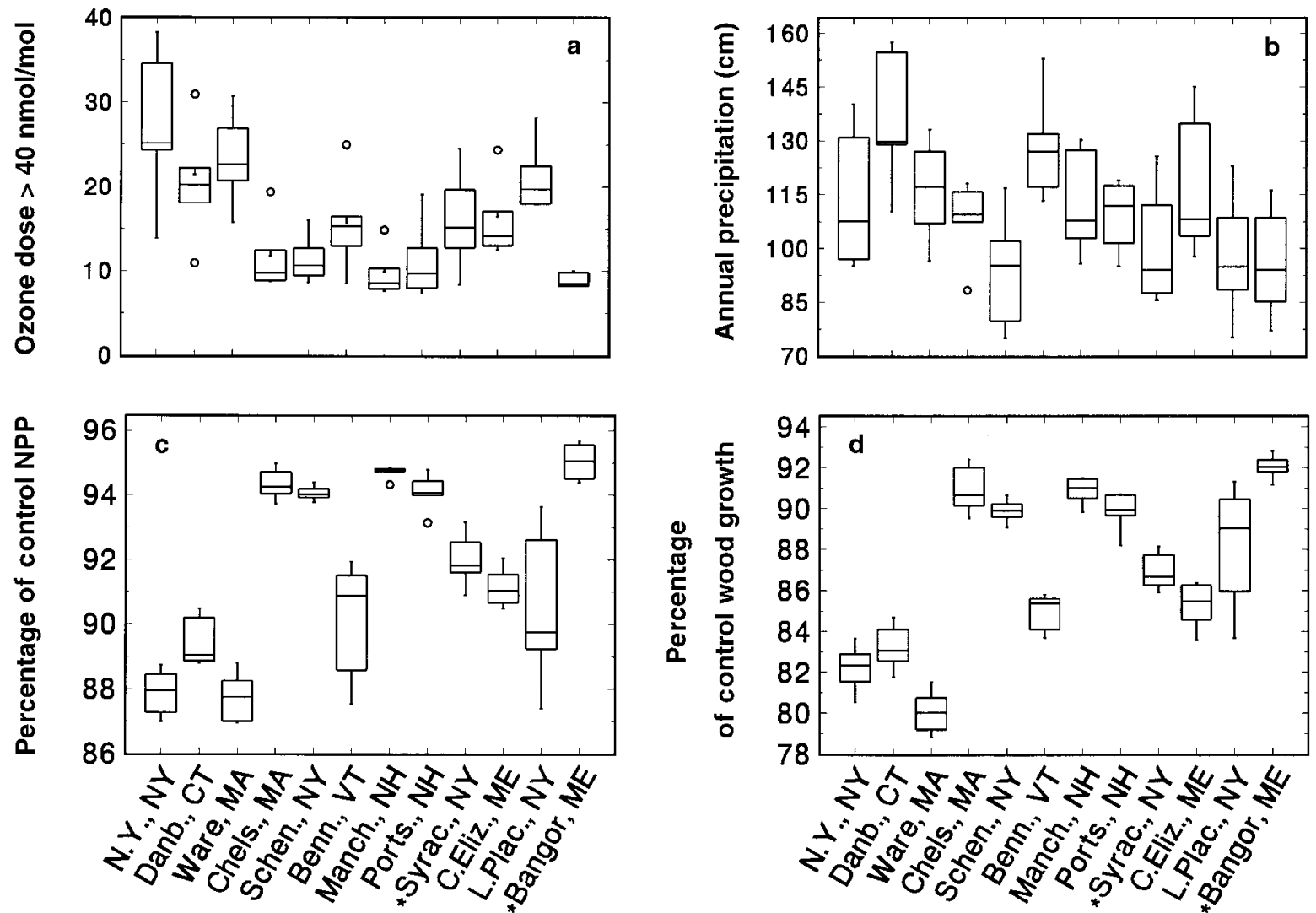

FIG. 8. Distributions of (a) ozone D40, (b) annual precipitation, (c) percentage change in NPP, and (d) percentage change in wood production across the 6-yr period from 1987 to 1992 for all 12 study sites. Boxes show median values and quartile ranges. Vertical lines show adjacent values, and circles are outliers. See Table 2 for descriptions of sites. Asterisks indicate rural sites located near the town or city listed.

as FolN increased from 1.8 to $2.6 \mathrm{mg} / \mathrm{g}$ (Fig. 9a). Similarly, model sensitivity to WHC tended to be greatest at high FolN where large transpirational demands led to rapid depletion of soil water. At low FolN, water limitations were less common and so WHC had less influence on predicted ozone damage. The mean decline in regional NPP under the full range of FolN and WHC was $7.6 \%(\mathrm{SD}=1.02)$, similar to the value obtained using average FolN and WHC values (Table 3 ).

Imposing an ozone effect on allocation to foliage did not change the nature of interactions between FolN and WHC, but did cause an increase in model sensitivity to WHC (Fig. 9b). Across the lower end of WHC values used $(2-16 \mathrm{~cm})$, predicted ozone injury was less than or equal to predictions made under standard assumptions. This was due to a subtle feedback that occurred between ozone and drought stress. At low WHC, the reduction in foliar biomass imposed by the BudC effect caused a small decrease in the transpirational water demand. Where this occurred, the loss of photosynthetically active leaf area was offset by a decrease in drought stress. At higher WHC, where drought was less common, this trade-off was not important and ozoneinduced declines in foliar biomass led to greater total injury. The mean decline in regional NPP under this scenario was $8.03 \%(\mathrm{SD}=4.33)$.

Imposing an ozone effect on stomatal conductance and water use efficiency caused significant changes in both the location and magnitude of ozone injury (Fig. 9c). Most noticeable is the fact that ozone injury was no longer greatly offset by water limitations at low WHC. Instead, ozone injury exacerbated water limitations, and this had the greatest effect on dry sites. At $\mathrm{WHC}=2$, ozone injury caused more than a $12 \%$ decline in predicted NPP, roughly twice that observed in the previous two scenarios. Lower levels of injury occurred towards the endpoint of low FolN and high WHC where water availability was high and transpirational demands were low. As in the previous two scenarios, the greatest growth declines occurred at high FolN and high WHC where ozone uptake was at its maximum. In this case, uptake was further elevated by the lack of stomatal down-regulation following reductions in photosynthesis. The mean decline in regional NPP under this scenario was $11.43 \%(\mathrm{SD}=5.0)$.

\section{CONCLUSIONS}

In this study, we synthesized information regarding plant response to ozone and applied it in a modeling 

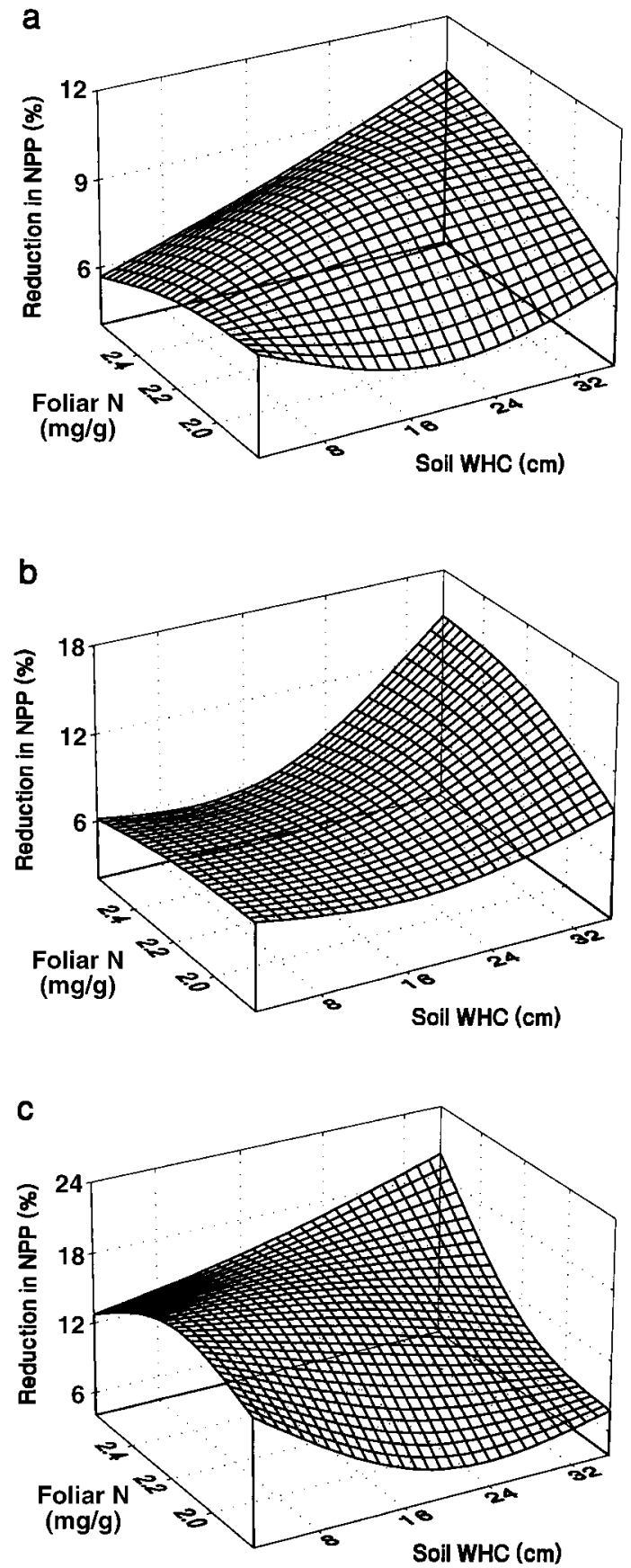

FIG. 9. Results of Monte Carlo sensitivity analyses showing the regional mean ozone effect on NPP (net primary production) in relation to variation in foliar $\mathrm{N}$ and soil WHC (water-holding capacity). Results are shown for three scenarios indicating model behavior under (a) standard PnET$\mathrm{O}_{3}$ configuration, (b) the BudC effect where allocation to foliage is no longer prioritized above wood and root growth, and (c) the water use efficiency effect where ozone exposure causes a gradual decline in stomatal function and water use efficiency. framework to mature hardwood forests growing under ambient conditions. Our approach was to summarize leaf-level ozone effects on carbon uptake in a forest productivity model that was designed to simulate the growth of mature, closed-canopy forests. Model runs using $6 \mathrm{yr}$ of concentration data from 64 sites across the northeastern United States indicate reductions in annual dry matter accumulation of between 3 and $16 \%$ for the period of 1987-1992 (mean $=7.4 \%$ ). Reductions in predicted wood production ranged from 3 to $22 \%$ (mean $=12.2 \%)$.

In general, growth declines were greatest near urban areas in southern portions of the region and in locations where drought stress was absent. Canopy ozone gradients had little effect because ozone depletion was minimal through the upper canopy layers where light levels and stomatal conductance were greatest. Yearto-year variation in predicted growth declines was small because there was a tendency for ozone and stomatal conductance to be inversely correlated on a temporal basis. Periods of high ozone often occurred during hot, dry weather conditions, which induced drought stress and limited ozone uptake. Although ozone effects were greatly moderated by variation in climate and soil moisture, growth reductions were substantial even under the driest conditions simulated.

Sensitivity analyses demonstrated how model behavior is influenced by several important assumptions and how predictions might be affected if those assumptions prove wrong. Results of these analyses revealed interactions between foliar nitrogen and soil water-holding capacity whereby model sensitivity to one of these parameters depended on the value of the other. Adding an ozone effect on allocation to foliage did not greatly alter the mean regional growth response, but did cause an increase in sensitivity to available soil water. Adding an ozone effect on stomatal function and plant water use efficiency altered both the nature and magnitude of predicted growth declines. In particular, the ozone-water interaction observed under standard model configuration was replaced by a situation in which ozone caused an increase in transpirational water loss and hence drought stress. The mean regional growth decline under this scenario was $11.4 \%$. Although the standard assumptions used in the model may be reasonable given available data and current ozone levels, these results demonstrate the need for additional field research on mature forest stands. Such work will be necessary for improving our understanding of important processes and for assessing the accuracy of model predictions.

\section{ACKNOWLEDGMENTS}

This research was conducted with support from the U.S.D.A. Forest Service Northern Global Change Program. We thank J. W. Munger for providing canopy ozone profile data and R. Poirot of the Northeast States for Cooperative Air Use Management (NESCAUM) for help in obtaining hourly ozone data. 


\section{Literature Cited}

Aber, J. D., and C. A. Federer. 1992. A generalized, lumpedparameter model of photosynthesis, evapotranspiration and net primary production in temperate and boreal forest ecosystems. Oecologia 92:463-474.

Aber, J. D., S. V. Ollinger, C. A. Federer, P. B. Reich, M. L. Goulden, D. W. Kicklighter, J. M. Melillo, and R. G. Lathrop. 1995. Predicting the effects of climate change on water yield and forest production in the northeastern U.S. Climate Research 5:207-222.

Aber, J. D., P. B. Reich, and M. L. Goulden. 1996. Extrapolating leaf $\mathrm{CO}_{2}$ exchange to the canopy: a generalized model of forest photosynthesis validated by eddy correlation. Oecologia 106:257-265.

Abrams, M. D., J. C. Schultz, and K. W. Kleiner. 1990. Ecophysiological response in mesic versus xeric hardwood species to an early-season drought in central Pennsylvania. Forest Science 36:970-981.

Amthor, J. S., D. S. Gill, and F. H. Bormann. 1990. Autumnal leaf conductance and apparent photosynthesis by saplings and sprouts in a recently disturbed northern hardwood forest. Oecologia 84:93-98.

Aubuchon, R. R., D. R. Thompson, and T. M. Hinckley. 1978. Environmental influences on photosynthesis within the crown of a white oak. Oecologia 35:295-306.

Baldocci, D. D., S. B. Verma, and D. E. Anderson. 1987. Canopy photosynthesis and water-use efficiency in a deciduous forest. Journal of Applied Ecology 24:251-260.

Chen, C. W., W. T. Tsai, and L. E. Gomez. 1994. Modeling responses of ponderosa pine to interacting stresses of ozone and drought. Forest Science 40:267-288.

Dobson, M. C., G. Taylor, and P. H. Freer-Smith. 1990. The control of ozone uptake by Picea abies (L.) Karst. and $P$. sitchensis (Bong.) Carr. during drought and interacting effects on shoot water relations. New Phytologist 116:465474.

Edwards, G. S., S. D. Wullschleger, and J. M. Kelly. 1994. Growth and physiology of northern red oak: preliminary comparison of mature tree and seedling responses to ozone. Environmental Pollution 83:215-221.

Ellsworth, D. S., and P. B. Reich. 1993. Canopy structure and vertical patterns of photosynthesis and related leaf traits in a deciduous forest. Oecologia 96:169-178.

Federer, C. A., and D. Lash. 1978. BROOK: a hydrologic simulation model for eastern forests. University of New Hampshire Water Resources Research Center Report 19.

Federer, C. A. 1982. Frequency and intensity of drought in New Hampshire forests: evaluation by the BROOK model. In Applied Modeling in Catchment Hydrology, Proceedings of the International Symposium on Rainfall-runoff Modeling, May 1981, Water Resources Publications, Littleton, Colorado, USA.

Field, C., and H. A. Mooney. 1986. The photosynthesisnitrogen relationship in wild plants. Pages $25-55$ in T. Givnish, editor. On the economy of plant form and function. Cambridge University Press, Cambridge, UK.

Fredericksen, T. S., B. J. Joyce, J. M. Skelly, K. C. Steiner, T. E. Kolb, K. B. Kouterick, J. E. Savage, and K. R Snyder. 1994. Physiology, morphology, and ozone uptake of leaves of black cherry seedlings, saplings, and canopy trees. Environmental Pollution 89:273-283.

Fuhrer, J. 1994. The critical level for ozone to protect agricultural crops - an assessment of data from European open-top chamber experiments. Pages 42-57 in: J. Fuhrer and B. Achermann, editors. Critical levels for ozone: a UN-ECE workshop report. Swiss Federal Research Station for Agricultural Chemistry and Environmental Hygiene, Liebefeld-Bern, Switzerland.

Guderian, R., D. T. Tingey, and R. Rabe. 1985. Effects of photochemical oxidants on plants. In R. Guderian, editor.
Air pollution by photochemical oxidants: formation, transport, control, and effects on plants. Springer-Verlag, Berlin, Germany.

Heck, W. W., O. C. Taylor, and D. T. Tingey, editors. 1988. Assessment of crop loss from air pollutants. Elsevier Applied Science, New York, New York, USA.

Hinckley, T. M., R. G. Aslin, R. R. Aubuchon, C. L. Metcalf, and J. E. Roberts. 1978. Leaf conductance and photosynthesis in four species of the oak-hickory type. Forest Science 24:73-84.

Hogsett, W. E., M. Plocher, V. Wildman, D. T. Tingey, and J. P. Bennett. 1985. Growth response of two varieties of slash pine seedlings to chronic ozone exposures. Canadian Journal of Botany 63:2369-2376.

Laisk, A., O. Kull., and H. Moldau. 1989. Ozone concentration in leaf intercellular air spaces is close to zero. Plant Physiology 90:1163-1167.

Laurence, J. A., R. G. Amundson, A. L. Friend, E. J. Pell, and P. J. Temple. 1994. Allocation of carbon in plants under stress: an analysis the ROPIS experiments. Journal of Environmental Quality. 23:412-417.

Laurence, J. A., R. J. Kohut, and R. G. Amundson. 1993. Use of TREGRO to simulate the effects of ozone on growth of red spruce seedlings. Forest Science 39:453-464.

Martin, M. E., and J. D. Aber. 1997. High spectral resolution remote sensing of forest canopy lignin, nitrogen, and ecosytem processes. Ecological Applications 7:431-443.

McLaughlin, S. B., and D. J. Downing. 1995. Interactive effects of ambient ozone and climate measured on growth of mature forest trees. Nature 374:252-254.

McLaughlin, S. B., P. A. Layton, M. B. Adams, N. T. Edwards, P. J. Hanson, E. G. O'Neill, and W. K. Roy. 1994. Growth responses of 53 open-pollinated loblolly pine families to ozone and acid rain. Journal of Environmental Quality 23: 247-257.

Mooney, H. A., and W. E. Winner. 1991. Partitioning response of plants to stress. Pages 129-141 in H. A. Mooney et al., editors. Response of plants to multiple stress. Academic Press, San Diego, California, USA. pp.

Munger, J. W., S. C. Wofsy, P. S. Bakwin, S. Fan, M. L. Goulden, B. C. Daube, A. H. Goldstein, K. Moore, and D. Fitzjarrald. 1996. Atmospheric deposition of reactive nitrogen oxides and ozone in a temperate deciduous forest and a sub-arctic woodland. 1. Measurements and mechanisms. Journal of Geophysical Research 101:12 63912657.

National Research Council. 1992. Rethinking the ozone problem in urban and regional air pollution. National Academy Press, Washington, D.C., USA.

Ollinger, S. V., J. D. Aber, C. A. Federer, G. M. Lovett, and J. Ellis. 1995. Modeling physical and chemical climatic variables across the northeastern U.S. for a Geographic Information System. USDA Forest Service General Technical Report NE-191.

Pell, E. J., N. Eckerdt, and A. J. Enyedi. 1992. Timing of ozone stress and resulting status of ribulose bisphosphate carboxylase/oxygenase and associated net photosynthesis. New Phytologist 120:397-405.

Pell, E. J., P. J. Temple, A. L. Friend, H. A. Mooney, and W. E. Winner. 1994. Compensation as a plant response to ozone and associated stresses: an analysis of ROPIS experiments. Journal of Environmental Quality 23:429436.

Pye, J. M. 1988. Impact of ozone on the growth and yield of trees: a review. Journal of Environmental Quality 17: 347-360.

Raich, J. W., and K. J. Nadelhoffer. 1989. Belowground carbon allocation in forest ecosystems: global trends. Ecology 70:1346-1354. 
Reich, P. B. 1987. Quantifying plant response to ozone: a unifying theory. Tree Physiology 3:63-91

Reich, P. B., and R. G. Amundson. 1985. Ambient levels of ozone reduce net photosynthesis in tree and crop species. Science 230:566-570.

Reich, P. B., D. S. Ellsworth, B. D. Kloeppel, J. H. Fownes, and S. T. Gower. 1990. Vertical variation in canopy structure and $\mathrm{CO}_{2}$ exchange of oak-maple forests: influence of ozone, nitrogen, and other factors on simulated canopy carbon gain. Tree Physiology 7:329-345.

Reich, P. B., B. Kloeppel, D. S. Ellsworth, and M. B. Walters. 1995. Different photosynthesis-nitrogen relations in deciduous and evergreen coniferous tree species. Oecologia 104:24-30

Reich, P. B., and J. P. Lassoie. 1984. Effects of low level O exposure on leaf diffusive conductance and water-use ef ficiency in hybrid poplar. Plant, Cell and Environment 7 661-668.

Reich, P. B., and J. P. Lassoie. 1985. Influence of low concentrations of ozone on growth, biomass partitioning and leaf senescence in young hybrid poplar plants. Environmental Pollution 39:39-51.

Sinclair, T. R., C. B. Tanner, and J. M. Bennet. 1984. Wateruse efficiency in crop production. BioScience 34:36-40

Skarby, L., G. Wallin, G. Sellden, P. K. Karlsson, S. Ottosson, S. Sutinen, and P. Grennfelt. 1995. Tropospheric ozonea stress factor for Norway spruce in Sweden. In H. Staff and G. Tyler, editors. Effects of acid deposition and tro- pospheric ozone on forest ecosystems in Sweden. Ecological Bulletins (Copenhagen) 44:133-146.

Taylor, G. E., Jr., and P. J. Hanson. 1992. Forest trees and tropospheric ozone: role of canopy deposition and leaf uptake in developing exposure-response relationships. Agriculture, Ecosystems and Environment 42:255-273.

Thorne, L., and G. P. Hanson. 1972. Species differences in rates of vegetal ozone absorption. Environmental Pollution 3:303-312.

Tjoelker, M. G., J. C. Volin, J. Oleksyn, and P. B. Reich. 1995. Interaction of ozone pollution and light effects on photosynthesis in a forest canopy experiment. Plant, Cell and Environment 18:895-905.

Volin, J. C., M. G. Tjoelker, J. Oleksyn, and P. B. Reich. 1993. Light environment alters response to ozone stress in seedlings of Acer saccharum Marsh and hybrid Populus L. II. Diagnostic gas exchange and leaf chemistry. New Phytologist 124:637-646

Wang, D., D. F. Karnosky, and F. H. Bormann. 1986. Effects of ambient ozone on the productivity of Populus tremuloides Michx. grown under field conditions. Canadian Journal of Forest Research 16:47-55.

Weinstein, D. A., and R. D. Yanai. 1994. Integrating the effects of multiple stresses on plants using the simulation model TREGRO. Journal of Environmental Quality 23: $418-428$.

Winner, W. E. 1994. Mechanistic analysis of plant response to air pollution. Ecological Applications 4:651-661. 